\title{
Socio-economic inequalities in children's snack consumption and sugar-sweetened beverage consumption: the contribution of home environmental factors
}

\author{
Wilke J. C. van Ansem ${ }^{1,2 *}$, Frank J. van Lenthe ${ }^{2}$, Carola T. M. Schrijvers ${ }^{1,2}$, Gerda Rodenburg ${ }^{1,2}$ and \\ Dike van de Mheen ${ }^{1,2,3}$ \\ ${ }^{1}$ IVO Addiction Research Institute, Heemraadssingel 194, 3021 DM Rotterdam, The Netherlands \\ ${ }^{2}$ Erasmus University Medical Centre, PO Box 2040, 3000 CA Rotterdam, The Netherlands \\ ${ }^{3}$ Department of Health Education and Promotion, Maastricht University, Maastricht, The Netherlands
}

(Submitted 11 September 2013 - Final revision received 23 December 2013 - Accepted 25 March 2014 - First published online 15 May 2014)

\section{Abstract}

In the present study, we examined the association between maternal education and unhealthy eating behaviour (the consumption of snack and sugar-sweetened beverages (SSB)) and explored environmental factors that might mediate this association in 11-year-old children. These environmental factors include home availability of snacks and SSB, parental rules about snack and SSB consumption, parental intake of snacks and SSB, peer sensitivity and children's snack-purchasing behaviour. Data were obtained from the fourth wave of the INPACT (IVO Nutrition and Physical Activity Child cohorT) study (2011), in which 1318 parent-child dyads completed a questionnaire. Data were analysed using multivariate regression models. Children of mothers with an intermediate educational level were found to consume more snacks than those of mothers with a high educational level $(B=1 \cdot 22, P=0 \cdot 02)$. This association was not mediated by environmental factors. Children of mothers with a low educational level were found to consume more SSB than those of mothers with a high educational level $(B=0.63, P<0.01)$. The association between maternal educational level and children's SSB consumption was found to be mediated by parental intake of snacks and SSB and home availability of SSB. The home environment seems to be a promising setting for interventions on reducing socio-economic inequalities in children's SSB consumption.

Key words: Home environmental determinants: Sugar-sweetened beverage consumption: Snack consumption: Socio-economic status: Peer influence: Food purchasing

Childhood overweight and obesity are major health issues in many countries, not only because of their high prevalence rates, but also because they are related to several negative health outcomes in adulthood ${ }^{(1-4)}$. One factor contributing to the rising prevalence of overweight and obesity in children and adolescents is the high consumption of sugar-sweetened beverages (SSB) and energy-dense snacks ${ }^{(5)}$ : a US study has found that $84 \%$ of adolescents consume an average of $887 \mathrm{ml}(30 \mathrm{oz})$ of SSB every day - equivalent to $16 \%$ of their total energy intake ${ }^{(6)}$. European studies carried out in The Netherlands, Hungary and Belgium have reported mean daily intakes of $350 \mathrm{ml}$ for girls and $500 \mathrm{ml}$ for boys and high consumption of soft drinks (more than $450 \mathrm{ml} / \mathrm{d}$ ) ${ }^{(7,8)}$. With regard to the consumption of energy-dense snacks, children in the USA have been found to consume nearly three snacks per d, with snacking accounting for up to $27 \%$ of their daily energy intake ${ }^{(9)}$. As children's and adolescents' dietary habits track into adulthood ${ }^{(10,11)}$, it is important to establish healthy eating habits at an early age. However, to develop effective interventions for reducing the consumption of energy-dense snacks and SSB, it is necessary to first understand the factors that influence children's dietary behaviour.

In recent years, research on children's dietary behaviour has focused more on environmental determinants. The environment has been defined as 'everything outside the individual', which had been structured in a framework for obesity-related research in the ANGELO (Analysis Grid for Environments Linked to Obesity) model ${ }^{(12)}$. Following this model, environments can be divided into two levels (micro and macro) and four types (socio-cultural, economic, political and physical). With respect to the levels, the influence of children's environment is largely confined by their micro-environment, such as the home environment and the neighbourhood environment. For children, especially young ones, the home food environment has a major influence on the development of their dietary behaviour ${ }^{(13)}$ : parents determine which food is

Abbreviations: INPACT, IVO Nutrition and Physical Activity Child cohorT; SES, socio-economic status; SSB, sugar-sweetened beverage.

*Corresponding author: W. J. C. van Ansem, fax +31 10276 3988, email vanansem@ivo.nl 
available at home, can set rules on what their children are allowed to eat, and can act as role models, also with respect to the dietary behaviour ${ }^{(14)}$. It has been found in studies investigating the associations between aspects of the home food environment and children's snack and SSB intake that children's consumption is influenced by the home availability of SSB and energy-dense snacks, by parents' own intake of snacks and SSB, and by family food rules regarding snacks and $\operatorname{SSB}^{(13,15-19)}$

In most of the Western countries, during the transition from childhood to adolescence (10-12 years), children now have considerable autonomy and decision-making power regarding their dietary behaviour ${ }^{(13,20)}$. They spend a lot of time with their friends and get pocket money they may use to purchase unhealthy foods. Therefore, it is likely that dietary behaviour in this age group is determined not only by the home food environment, but also by children's food-purchasing behaviour and their peers' dietary behaviour. Although little research has been carried out on peer influence on children's energy-dense snack and SSB consumption, peer-group snack and soft drink consumption has been found to be associated with the intake of SSB and snacks among adolescents aged 12-17 years $^{(21)}$. Previous findings of the INPACT (IVO Nutrition and Physical Activity Child cohorT) study have also indicated that children who are sensitive to peer influence consume more snacks than their counterparts who are not sensitive to $\mathrm{it}^{(22)}$. Similarly, a recent review by Fletcher et al. ${ }^{(23)}$ has concluded that school friendships may be critical in shaping adolescents' eating behaviour.

Although little is known about the role of economic factors in children's dietary behaviour, it is generally assumed that parents make decisions that can be influenced by economic determinants, although they leave some of these decisions to their children ${ }^{(24)}$. For instance, parents provide pocket money for their children to spend on items of their own choice. In The Netherlands, $82 \%$ of children aged 6-7 years receive pocket money ${ }^{(25)}$. Those with access to pocket money have been reported to spend more on sweets and snacks ${ }^{(20,26)}$. Children who purchase snacks or sweets with their pocket money have been reported to also consume more energy-dense snacks than their counterparts who did not ${ }^{(22)}$. It has also been found that children who receive pocket money consume more soft drinks ${ }^{(24)}$.

Several studies have found associations between socioeconomic status (SES) and children's dietary behaviour, with low SES being found to be associated with unhealthy dietary patterns (snacks and fast food) in children and adolescents ${ }^{(27,28)}$. Children and adolescents with a lower SES have been reported to consume more soft drinks and to more likely be overweight than their counterparts with a high $\mathrm{SES}^{(29-31)}$. However, because SES is not an easily modifiable correlate of children's dietary behaviour and does not directly influence dietary behaviour, it is important to identify modifiable determinants of children's unhealthy dietary behaviour that may explain socio-economic inequalities in their energydense snack and SSB consumption. However, little literature is available on factors that explain socio-economic disparities in children's energy-dense snack and SSB consumption.

The overall aim of the present study was, therefore, to explore the extent to which various types of environmental factors explain socio-economic inequalities in 10- to 12-yearolds' SSB and energy-dense snack consumption. We examined the following: (1) the association between SES (maternal educational level) and children's SSB and energy-dense snack consumption; (2) whether the association between SES and children's energy-dense snack consumption is mediated by home environmental factors (home availability, food rules and parental intake), by economic factors (children's foodpurchasing behaviour), or by peer sensitivity; (3) whether the association between SES and children's SSB consumption is mediated by home environmental factors (home availability, food rules and parental intake) (Fig. 1). Because no proper data were available on SSB-purchasing behaviour and peer sensitivity regarding SSB consumption, we were unable to

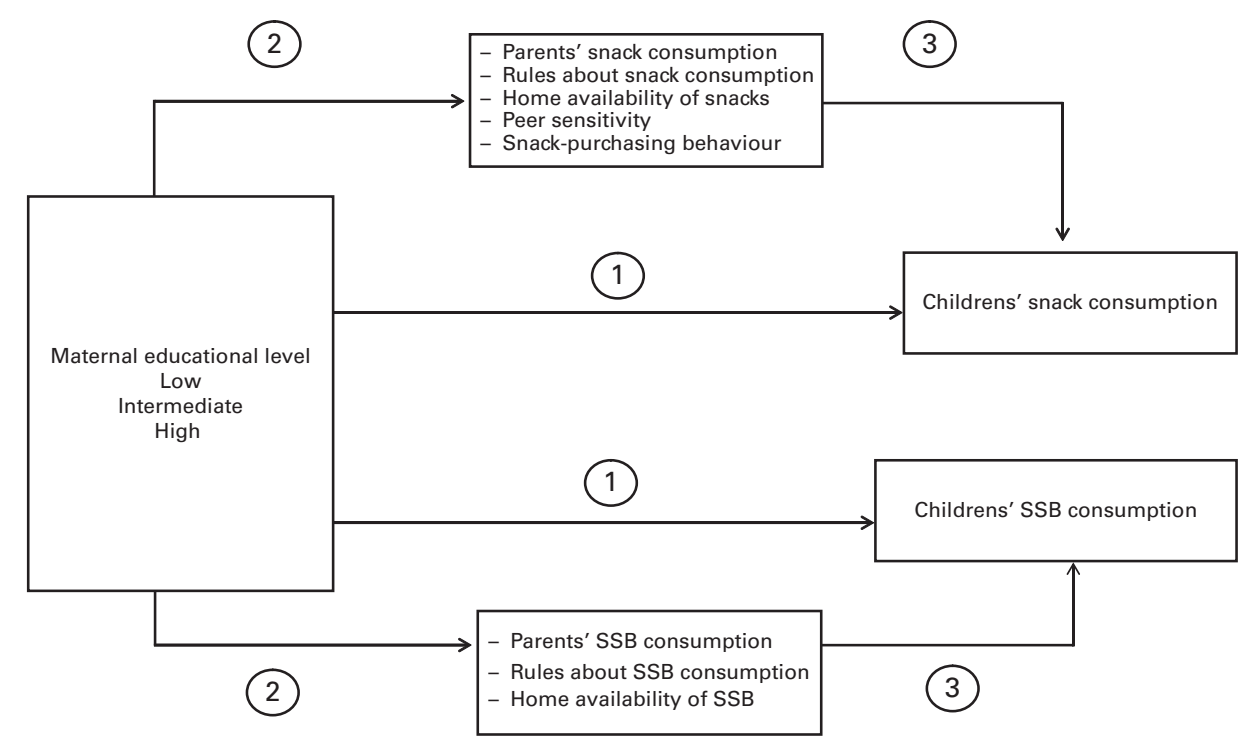

Fig. 1. Research model. SSB, sugar-sweetened beverage. 
explore their contribution to socio-economic inequalities in children's SSB consumption.

\section{Methods \\ Study population and design}

The data used in the present study were derived from the Dutch INPACT study. INPACT is a longitudinal study carried out among 8- to 12-year-olds and their parents to investigate modifiable environmental determinants of children's dietary behaviour and physical activity. The INPACT study had four annual data collection periods (2008-2011). The participants were recruited from primary schools in the southern part of The Netherlands (Eindhoven and surroundings). The municipal health service invited all primary schools in this area to participate in the study ( $n$ 265). A total of ninety-one primary schools (34.3\%) agreed to participate. The response by schools in urban and rural areas was similar. A total of 1844 parentchild dyads (62.5\%) gave informed consent. Trained research assistants visited the participating schools and measured children's height and weight. The children completed a short questionnaire at school and the parents completed a questionnaire at home. The questionnaire topics differed annually. The INPACT study was approved by the Medical Ethics Committee at Erasmus University Medical Centre Rotterdam. The present study was based on the data collected in the last wave (2011), in which a questionnaire was completed by 1428 parents (77.5\%) and 1575 children (85.4\%).

\section{Measurements}

Maternal educational level. In the present study, we used maternal educational level as an indicator of SES, as it is one of the three commonest indicators of SES and has been found to be the strongest and most consistent SES indicator for predicting health-related behaviour ${ }^{(32)}$. Maternal educational level was classified into three groups: 'low educational level' (primary school and lower secondary education); 'intermediate educational level' (intermediate vocational level, higher secondary school and pre-university education); 'high educational level' (higher vocational education and university). In the remainder of this article, we refer to these groups as 'low SES' (children of mothers with a low educational level), 'intermediate SES' (children of mothers with an intermediate educational level) and 'high SES' (children of mothers with a high educational level).

Outcome measurements (children's snack and sugarsweetened beverage consumption). To measure children's snack and SSB consumption, we used questionnaires based on the validated $\mathrm{FFQ}^{(33,34)}$. Children's snack consumption was measured based on their reports, and their SSB consumption was measured based on their parents' reports (no children's reports were available on SSB consumption). It was reported how many days in the past $7 \mathrm{~d}$ the children had consumed the following items between meals: (1) savoury snacks (e.g. potato chips, peanuts or sausage rolls); (2) sweet snacks (e.g. candy bars, chocolate or candies); (3) cake or large biscuits; (4) SSB. The answer categories ranged from 'none or less than $1 \mathrm{~d}$ a week' to ' $7 \mathrm{~d}$ a week'. Additionally, the number of items that the children had consumed on such a day was reported. For savoury snacks, sweet snacks, and cake or large biscuits, the answer categories ranged from ' 0 items per d' to ' 10 items or more per d'. For SSB, the answer categories ranged from ' 0 glasses per d' to 'more than 5 glasses per d', by increments of half a glass. A reported intake of more than five glasses per week ( $n 7)$ was recoded as six glasses. In the questionnaire, it was specified that one glass equals $200 \mathrm{ml}$, that one can equals $330 \mathrm{ml}$ or 1.5 glasses, and that one bottle equals $500 \mathrm{ml}$ or 2.5 glasses. Children's total snack consumption was calculated in items per week by multiplying the consumption frequencies of savoury snacks, sweet snacks and cakes with their corresponding quantities and summing these scores. Children's SSB consumption was calculated in servings per week by multiplying frequencies and quantity.

\section{Potential mediating variables}

Parental intake of snacks and sugar-sweetened beverages. Parental intake of snacks and SSB was measured and calculated in the same way as children's snack and SSB consumption; it was reported by the parents.

Snack and sugar-sweetened beverage consumption rules. The parents were asked whether they had set rules about (1) the number of snacks and (2) the number of SSB that their children could consume. The answer categories were 'yes' and 'no'. These questions were derived from the ENDORSE study ${ }^{(35)}$

Home availability of snacks and sugar-sweetened beverages. The availability of snacks and SBB at home was measured using a questionnaire based on the validated Home Environment Survey ${ }^{(36)}$. The parents were asked to report how often (1) sweet snacks and biscuits, (2) savoury snacks and (3) SBB were available at home. The answer categories were 'always available', 'usually available', 'sometimes available', 'usually not available' and 'never available'. Due to limited variation in this variable, we dichotomised the response categories into 'always available' and 'not always available'. We created one variable for the home availability of snacks, for which we merged the home availability of sweet snacks and that of savoury snacks into one variable. Due to limited variation in these variables, we dichotomised the response categories into 'snacks always available at home' (at least sweet snacks and biscuits or savoury snacks were always available at home) $v$. 'snacks not always available at home' (neither sweet snacks and biscuits nor savoury snacks were always available at home).

Snack-purchasing behaviour. The children were asked what they usually bought with their pocket money. There were ten answer categories including 'sweet snacks' and 'savoury snacks'; most of the other categories were related to non-food items (e.g. 'toys', 'computer games' or 'books'). The children were allowed to choose more than one answer category. We created a dichotomous variable 'purchasing snacks' with the answer categories 'yes' (children bought sweet snacks and/or savoury snacks) and 'no'. Children who did not receive pocket money ( $n$ 267, 18.7\%) were classified as those 'purchasing no snacks'. 
Peer sensitivity. To measure the influence of peers on children's dietary intake, we presented the children with the following hypothetical situation: "After school, you are with some friends. You and your friends decide to go to a supermarket or fast-food restaurant. While you don't intend to buy any snacks, you decide to join your friends. When they're in the supermarket or fast-food restaurant, all your friends buy snacks.' We asked the children how they would act in such a situation. They were given two response options: 'Then I'll buy some food, too' or 'I won't buy any food'. We named the answer categories 'peer sensitivity' ('Then I'll buy some food, too') and 'peer sensitivity' ('I won't buy any food').

Control variables. Because children's age, sex, ethnicity and BMI might be associated with the dependent and independent variables, they were considered as potential confounders.

Children's age was calculated on the basis of the date of birth and the date of measurement. For the purpose of analysis, we dichotomised children's age into ' $\leq 11$ years' $v$. '>11 years'. Children's ethnicity was categorised into 'Dutch native' (both parents born in The Netherlands) and 'immigrants' (at least one of the parents was born outside The Netherlands). Children's BMI was calculated on the basis of their weight and height, which were measured with clothes but without shoes to the nearest $0.1 \mathrm{~kg}$ and $0.1 \mathrm{~cm}$; the measurements were made by trained research assistants. BMI cut-off points for children were used to define 'overweight' ('overweight' and 'obesity') $v$. 'non-overweight' ('underweight and normal weight') (37).

\section{Data analyses}

Respondents who lacked maternal educational level data were excluded from the analysis ( $n$ 110, 7·7\%). Descriptive analyses were carried out to describe the characteristics of the study population.

To investigate whether environmental factors mediated the association between maternal educational level and children's energy-dense snack and SSB consumption, we used Baron \& Kenny's ${ }^{(38)}$ four-step approach. According to Baron and
Kenny, there are three criteria for mediation: (1) the predictive variable has to be associated with the outcome variable; (2) the predictive variable has to be associated with the mediator, (3) the mediator has to be associated with the outcome variable (adjusted for the predictive variable). If all the associations assessed in steps 1-3 are statistically significant, the criteria for mediation have been met. Step 4 of the approach involves testing the mediation model: mediation is supported if the association between the predictive variable and the outcome variable changes after controlling for the mediator ${ }^{(38)}$.

The steps of the mediation analysis were conducted separately for each outcome measure (children's snack consumption and children's SSB consumption). Depending on the scale of the outcome measures, logistic regression models or linear regression models were used to test the subsequent steps of the mediation approach. Several potential mediators were tested for each outcome measure. If it appeared that more than one potential mediator met the criteria for mediation, the unique contribution of each mediator was determined (single-mediator model). Next, a multivariate mediation model was tested. Bootstrap resampling techniques were used to calculate CI for the mediated effects.

All the analyses were adjusted for potential confounders. The regression analyses were carried out using IBM SPSS Statistics version 20, and the bootstrapping analyses were carried out using R (2013). Due to missing values, the computed models for snack and SSB consumption differ with regard to the numbers of participants.

\section{Results}

Most of the children were aged $\leq 11$ years; about half were boys. The majority were Dutch natives and were not overweight (Table 1). There were statistically significant SES differences in their background characteristics: (1) relative to the low-SES and high-SES groups, there were more girls in the intermediate-SES group and (2) relative to children with an intermediate or high SES, more children with a low SES were overweight, were aged $>11$ years and were immigrants.

Table 1. Characteristics of the study population (total sample and sample broken down) according to maternal educational level (Number of children and percentages)

\begin{tabular}{|c|c|c|c|c|c|}
\hline & Total sample & Low educational level & Intermediate educational level & High educational level & $P$ \\
\hline $\begin{array}{c}\text { Mean age }(n) \\
\leq 11 \text { years }\end{array}$ & 1317 & 263 & 628 & 426 & 0.00 \\
\hline$n$ & 1119 & 205 & 528 & 386 & \\
\hline$\%$ & 85.0 & 77.9 & $84 \cdot 1$ & 90.6 & \\
\hline \multicolumn{6}{|l|}{$>11$ years } \\
\hline$n$ & 198 & 58 & 100 & 40 & \\
\hline$\%$ & $15 \cdot 0$ & $22 \cdot 1$ & 15.9 & 9.4 & \\
\hline $\operatorname{Sex}(n)$ & 1318 & 263 & 629 & 426 & 0.02 \\
\hline Boys (\%) & $50 \cdot 8$ & 52.5 & $46 \cdot 7$ & 55.6 & \\
\hline Girls (\%) & $49 \cdot 2$ & 47.5 & 53.3 & 44.4 & \\
\hline Children's BMI $(n)$ & 1283 & 252 & 616 & 415 & 0.01 \\
\hline Overweight (\%) & $11 \cdot 2$ & $16 \cdot 7$ & $10 \cdot 6$ & 8.9 & \\
\hline Non-overweight (\%) & 88.8 & 83.3 & 89.4 & 91.9 & \\
\hline Children's ethnicity $(n)$ & 1318 & 263 & 629 & 426 & 0.02 \\
\hline Native Dutch (\%) & 88.8 & 84.4 & 90.9 & 89.4 & \\
\hline Immigrant (\%) & 11.2 & $15 \cdot 6$ & 9.1 & $10 \cdot 6$ & \\
\hline
\end{tabular}




\section{Snack consumption}

While high-SES children exhibited the lowest mean snack consumption ( $9 \cdot 0$ items a week), those with an intermediate SES exhibited the highest (10.2 items) (univariate analyses; Table 2). Multivariate analyses revealed that, per week, children with an intermediate SES consumed more snacks $(B=1 \cdot 22,95 \%$ CI $0 \cdot 22,2 \cdot 20)$ than those with a high SES. There was no statistically significant difference in snack consumption between children with a low SES and those with a high SES. Because none of the potential mediators was associated with maternal educational level, the criteria for mediation were not met, and the further steps of the mediation analysis were not conducted.

\section{Sugar-sweetened beverage consumption}

The highest mean SSB consumption was observed in low-SES children (2.4 litres per week) and the lowest in high-SES children (1.8 litres per week) (Table 3). Multivariate analyses revealed that children with a low SES consumed 0.63 litres of SSB more per week than high-SES children (95\% CI 0.36, 0.91). There was no statistically significant difference in SSB consumption between children with an intermediate SES and those with a high SES.

Parents with an intermediate SES and parents with a low SES consumed more SSB and were more likely to always have SSB available at home than parents with a high SES. There was no statistically significant association between maternal educational level and SSB consumption rules. As this meant that the criteria for mediation were not met, the remaining steps of the mediation analysis were not conducted for SSB consumption rules.

Parental intake of SSB and home availability of SSB were significantly associated with children's SSB consumption: if their parents consumed 1 litre of SSB per week, children consumed 0.46 litres of SSB more per week. If SSB were always

Table 2. Regression analyses of snack consumption ( $n$ 1173)

(Unstandardised coefficients $(B)$ or odds ratios and $95 \%$ confidence intervals)

Multivariate regression analyses $\dagger$

$B$

$95 \% \mathrm{Cl}$

Step 1: Association between
maternal educational level and
children's snack consumption
Maternal educational level
High
Intermediate
Low
Step 2: Association between
maternal educational level and
potential mediating variables
Maternal educational level
High
Intermediate
Low

Children's mean intake of

snacks (items per week)

by maternal educational level

(unadjusted)

9.0
10.2
9.9

9.22

$1.22^{*}$

0.99

$0.22,2 \cdot 20$

Descriptives regarding possible mediating variables by maternal educational level (unadjusted)

Parents' mean snack intake (items per week)

$$
\begin{aligned}
& 5.9 \\
& 6.0 \\
& 5.6
\end{aligned}
$$

$$
\begin{array}{r}
5 \cdot 64 \\
0 \cdot 11 \\
-0.21
\end{array}
$$$$
-0.63,0.84
$$

OR

$-1 \cdot 13,0.72$

Maternal educational level

$$
\text { High }
$$

Intermediate

Low

Maternal educational level

$$
\begin{aligned}
& \text { High } \\
& \text { Intermediate } \\
& \text { Low } \\
& \text { Maternal educational level }
\end{aligned}
$$

High

Intermediate

Low

Maternal educational level

$$
\text { High }
$$

Intermediate

Low
Parents who set rules about snack consumption (\%) $72 \cdot 9$

73.2

$77 \cdot 0$

Snacks always available at home (\%)

$75 \cdot 3$
74.2
$75 \cdot 7$
Children who are sensitive
to peer influence $(\%)$
$61 \cdot 1$
$60 \cdot 5$
$60 \cdot 0$
Children who purchase food

(\%)

\footnotetext{
${ }^{*}$ Statistically significant association: children of mothers with an intermediate educational level consumed more snacks than those of mothers with a high educational level $(P=0.02)$.

† Multivariate regression analyses adjusted for children's age, sex, ethnicity and BMI.
} 


\section{N British Journal of Nutrition}

Table 3. Analyses of sugar-sweetened beverage (SSB) consumption ( $n$ 1266)

(Unstandardised coefficients $(B)$, odds ratios or percentage changes and $95 \%$ confidence intervals)

\begin{tabular}{|c|c|c|c|c|c|}
\hline & & \multicolumn{2}{|c|}{ Multivariate regression analyses } & & \\
\hline & & $B \dagger$ & $95 \% \mathrm{Cl}$ & & \\
\hline $\begin{array}{l}\text { Step 1: Association between maternal educational } \\
\text { level and children's SSB consumption }\end{array}$ & $\begin{array}{l}\text { Children's mean SSB consumption (litres } \\
\text { per week) by maternal educational } \\
\text { level (unadjusted) }\end{array}$ & & & & \\
\hline \multicolumn{6}{|l|}{ Maternal educational level } \\
\hline High & 1.8 & $2 \cdot 13$ & & & \\
\hline Intermediate & $2 \cdot 0$ & 0.17 & $-0.05,0.39$ & & \\
\hline Low & $2 \cdot 4$ & $0.63^{\star \star}$ & $0.36,0.91$ & & \\
\hline $\begin{array}{l}\text { Step 2: Association between maternal educational } \\
\text { level and potential mediating variables }\end{array}$ & $\begin{array}{l}\text { Descriptives regarding possible mediating } \\
\text { variables by maternal educational level } \\
\text { (unadjusted) }\end{array}$ & & & & \\
\hline Maternal educational level & Parents' mean SSB intake (litres per week) & & & & \\
\hline High & 0.7 & 0.51 & & & \\
\hline Intermediate & 0.9 & $0.24^{\star \star}$ & $0.06,0.43$ & & \\
\hline \multirow[t]{2}{*}{ Low } & $1 \cdot 3$ & $0.62^{* *}$ & $0.39,0.85$ & & \\
\hline & & ORt & $95 \% \mathrm{Cl}$ & & \\
\hline Maternal educational level & $\begin{array}{l}\text { Parents who set rules about SSB } \\
\text { consumption (\%) }\end{array}$ & & & & \\
\hline High & 67.9 & 1.00 & & & \\
\hline Intermediate & 70.6 & $1 \cdot 16$ & $0.88,1.52$ & & \\
\hline Low & 67.9 & 0.95 & $0.69,1.37$ & & \\
\hline Maternal educational level & SSB always available at home (\%) & & & & \\
\hline High & 59.7 & 1.00 & & & \\
\hline Intermediate & 69.0 & $1.51^{* *}$ & $1 \cdot 16,1.97$ & & \\
\hline \multirow[t]{2}{*}{ Low } & 74.0 & $2 \cdot 07^{\star \star}$ & $1.45,2.95$ & & \\
\hline & & $B \ddagger$ & $95 \% \mathrm{Cl}$ & & \\
\hline $\begin{array}{l}\text { Step 3: Association between possible mediating } \\
\text { variables and children's SSB intake }\end{array}$ & $\begin{array}{l}\text { Children's mean SSB consumption by } \\
\text { mediating variables (unadjusted) }\end{array}$ & & & & \\
\hline Parents' SSB intake & - & $0.46^{\star \star}$ & $0.40,0.52$ & & \\
\hline \multicolumn{6}{|l|}{ Home availability of SSB } \\
\hline Not always & 1.32 & 1.51 & & & \\
\hline \multirow[t]{2}{*}{ Always } & 2.35 & $0.96^{\star \star}$ & $0.77,1 \cdot 17$ & & \\
\hline & B model step 1 & Mediation model B $\dagger$ & $95 \% \mathrm{Cl}$ & $\begin{array}{l}\text { Percentage } \\
\text { change }\end{array}$ & $95 \% \mathrm{Cl}$ \\
\hline \\
\hline \multicolumn{6}{|l|}{$\begin{array}{l}\text { Step 4: Mediation model } \\
\text { Maternal educational level+ parents' SSB intake }\end{array}$} \\
\hline High & $2 \cdot 13$ & 1.90 & & & \\
\hline Intermediate & 0.17 & 0.06 & $-0.14,0.26$ & -65.5 & $-359 \cdot 74,204 \cdot 32$ \\
\hline Low & 0.63 & $0.34^{\star \star}$ & $0.09,0.60$ & $-45 \cdot 6^{\star \star}$ & $-79 \cdot 68,-25 \cdot 76$ \\
\hline Maternal educational level+home availability of $S$ & & & & & \\
\hline High & $2 \cdot 13$ & 1.51 & & & \\
\hline Intermediate & 0.17 & 0.08 & $-0.13,0.29$ & $-51 \cdot 6$ & $-513 \cdot 51,250 \cdot 18$ \\
\hline Low & 0.63 & $0.48^{\star \star}$ & $0.22,0.75$ & $-23 \cdot 7^{\star \star}$ & $-46 \cdot 82,-12 \cdot 68$ \\
\hline \multirow{2}{*}{\multicolumn{6}{|c|}{$\begin{array}{l}\text { Maternal educational level+ parents' SSB } \\
\text { intake + home availability of SSB }\end{array}$}} \\
\hline & & & & & \\
\hline High & $2 \cdot 13$ & 1.47 & & & \\
\hline Intermediate & 0.17 & 0.01 & $-0.19,0.20$ & $-96 \cdot 3$ & $-681 \cdot 20,301 \cdot 66$ \\
\hline Low & 0.63 & $0.26^{\star \star}$ & $0.01,0.52$ & $-58 \cdot 2^{\star \star}$ & $-102.70,-37.06$ \\
\hline
\end{tabular}

** Statistically significant association $(P<0.05)$

† Multivariate regression analyses adjusted for children's age, sex, ethnicity and BMI.

¥ Multivariate regression analyses adjusted for maternal educational level and children's age, sex, ethnicity and BM 
available at home, they consumed 0.96 litres of SSB more per week.

In the single-mediator model, home availability of SSB explained $23.7 \%$ of the socio-economic differences between children of mothers with a low educational level and those with a high educational level parental intake of SSB explained $45.6 \%$. In the multiple-mediator model, home availability of SSB and parental intake of SSB together explained $58.2 \%$ of the differences in SSB consumption between children with a low SES and those with a high SES. Home availability of SSB and parental intake of SSB did not significantly mediate SSB consumption between children of mothers with an intermediate educational level and those with a high educational level.

\section{Discussion}

The present results revealed snack and SSB consumption to be the lowest in children with a high SES, snack consumption to be the highest in those with an intermediate SES and SSB consumption to be the highest in those with a low SES. The association between maternal educational level and children's energy-dense snack consumption was not mediated by the environmental factors, because none of them differed between socio-economic groups. The association between maternal educational level and children's SSB consumption was mediated by the home availability of SSB and parental intake of SSB.

As has been stated above, we found socio-economic differences in children's energy-dense snack consumption. Unexpectedly, there was no ascending gradient in children's snack consumption, with children with an intermediate SES exhibiting the highest snack consumption. Nor was there a significant difference in snack consumption between children with a high SES and those with a low SES. Both these findings may be due to the difficulty of accurately measuring snack consumption, where the main problem is one of definition. As snacking is often defined as an eating occasion between meals, a snack can be any kind of food that is eaten between meals - for example, fruit is sometimes referred to as a healthy snack ${ }^{(39)}$. As snacks represent a broad range of foods, their nutrient and energy values can differ greatly between one snack and another and therefore be difficult to measure precisely.

In the present study, the term 'snacks' refers to unhealthy foods eaten between meals. To measure snack consumption as accurately as possible, we distinguished three categories of energy-dense snack - savoury snacks, sweet snacks, and cake or large biscuits - and gave examples of the type of foods that we considered as snacks in each category. Nevertheless, the energy intake from snacks remains unclear, and it is possible that children from lower SES backgrounds consumed more low-nutrient energy-dense snacks than those from higher ones. However, our findings that children with a high SES consumed fewer snacks than children from lower-SES groups are in line with those of previous studies ${ }^{(27,28)}$.

Contrary to our expectations, we found no association between maternal educational level and home environmental determinants of snacking (i.e. home availability of snacks, snack consumption rules and parental intake of snacks). This may also have been due to the same difficulty of defining snacks and may also affect the measurement of home environmental determinants of snacking. For example, it is conceivable that children from low-SES backgrounds have more high-energy snacks available at home than their counterparts from high-SES backgrounds, although this was not observed in the present study. It is also possible that the use of dichotomised variables (e.g. home availability of snacks) may be responsible for a lack of mediation effect in the association between maternal educational level and children's snack consumption. However, additional analyses (in which home availability of snacks was included as a measure with three answer categories) yielded comparable results. Nevertheless, future studies should use more extensive questionnaires to measure determinants of the home food environment instead of using binary variables.

Hardly any other studies have examined the association between environmental determinants of snack consumption and SES. To our knowledge, only a study carried out by Hupkens et al. ${ }^{(40)}$ explored whether food rules varied across maternal educational levels. They found that high-SES mothers were more likely to limit their children's intake of sweets and chips. However, due to differences in measurements, the results of the study carried out by Hupkens et al. are not comparable to those of the present study.

We found no association between maternal educational level and children's snack-purchasing behaviour. In fact, the present results revealed that only a small proportion of the children purchased snacks with their pocket money. This indicates that pocket money has only a limited influence on the dietary behaviour of primary school children (aged 10-12 years). As Dutch primary schools have no canteens or vending machines, children also have fewer opportunities to purchase snacks. The influence of pocket money on children's dietary behaviour may be greater in older adolescents, who have more autonomy and more opportunities to buy food. By interpreting the findings regarding pocket money, it should be mentioned that children who did not receive pocket money ( $n$ 267, 18.7\%) were classified as those 'purchasing no snacks'. However, this possibly biased the present results, as we do not know whether these children would buy snacks if they received pocket money. However, additional analyses in which children who received no pocket money were excluded yielded the same results.

The present results also revealed that peer sensitivity was not associated with children's SES. Although no other studies have examined whether the association between SES and children's dietary behaviour is mediated by peer sensitivity, the influence of peers on children's dietary behaviour has been studied among older children at secondary school $^{(21,41,42)}$. This may suggest that peers are likely to have more influence on dietary behaviour in older adolescents. Future studies could explore whether socio-economic differences in adolescents' dietary behaviour are explained by economic factors and peer sensitivity.

We explored whether the association between maternal educational level and children's SSB consumption was 
mediated by home environmental factors (parental intake of SSB, SSB consumption rules and home availability of SSB). In line with a recent study carried out by De Coen et al. ${ }^{(29)}$, we found that parental intake and home availability of SSB were indeed mediating factors. Unlike some previous studies, however, we found no associations between SES and SSB consumption rules ${ }^{(29,40)}$.

It is already known that home environmental determinants (including children's snack and SSB consumption) are important for the development of children's dietary behaviour. Our findings indicated that socio-economic disparities in children's SSB consumption can also be explained by home environmental factors. Because parents shape the home food environment (by deciding, for example, which food is available and by setting food rules) ${ }^{(14)}$, they not only play a crucial role in the development of their children's dietary behaviour, but are also important targets for health interventions. Interventions focusing on home environmental factors and the important role of parents may be able to reduce not only children's snack and SSB consumption but also socio-economic differences in children's SSB consumption. Although improvement of the home food environment may be a key factor through which interventions can improve children's dietary intake, little is known about effective ways to do this. However, a few community interventions have examined changes in children's home food environments. These interventions provide activities to engage families, and it has been found that this may provide added benefits to improve the home food environment ${ }^{(43,44)}$.

The present study has some limitations. First, except for the data on children's BMI, most of our data were derived from parents' or children's reports. By evoking socially desirable answers, these may lead to under-reporting of the outcome variables (children's snack consumption and children's SSB consumption) or of any of the potential mediating variables (home availability, rules and parental intake). If certain SES groups give a greater number of socially desirable responses, under-reporting of mediating variables can lead these variables to be underestimated as factors that explain socioeconomic differences in children's snack consumption. For example, because parents with a high SES are more likely to be more health-minded and to be more knowledgeable about healthy eating behaviour, they may also be likely to give more socially desirable responses. On the other hand, it is possible that parents and children from high socioeconomic backgrounds do indeed have more healthy eating patterns in which they consume fewer snacks and SSB. This would make it less likely that they gave socially desirable answers. Due to this and to our finding of associations between maternal educational level and home environmental determinants of SSB consumption, we do not expect socially desirable answers to explain why we found no associations between maternal educational level and home environmental determinants of snacking.

The second limitation is that we measured peer sensitivity on the basis of the children's answers to how they would act in a hypothetical situation; we did not measure their actual behaviour when they spent time with their friends.
It may be difficult for children, especially those with a low SES, to answer questions about a hypothetical situation. However, because trained research assistants were available to help them complete the questionnaire in the classroom, we believe that this would not have affected the results substantially. The questionnaire to measure peer sensitivity was developed for the present study, as, to our knowledge, no relevant child questionnaires are available. Future research should develop validated questionnaires to measure the influence of peers on children's and adolescents' dietary behaviour.

The third limitation is that we carried out statistical analyses based on a cross-sectional dataset that did not allow conclusions to be drawn about any causal relationships. However, as educational level is a consistent factor over time, it is highly unlikely that children's food consumption will affect a mother's educational level. Although it is possible that children's SSB consumption contributes to the amounts of SSB available at home or to parental intake of SSB, we believe that the impact of parental intake and home availability of snacks and SSB on children's consumption of snacks and $\mathrm{SSB}$ is greater. Therefore, we expect the directions of the associations we found to be as shown in Fig. 1.

Finally, in our analyses, we adjusted for some potential confounders, including children's BMI. As children's BMI is associated with many other factors, there is a risk of 'overadjusting' the associations under study. Adjustment of children's BMI may have erased part of the effect of SES and children's snack and SSB consumption. However, additional analyses in which we excluded children's BMI as a control variable yielded comparable results.

\section{Conclusion}

The present study found associations between maternal educational level and children's consumption of SSB and snacks, with children of mothers with a lower educational level (low and intermediate SES) exhibiting the least favourable behaviour. The association between maternal educational level and children's SSB consumption was mediated by parental intake of SSB and home availability of SSB.

Interventions to reduce children's SSB consumption, especially that of children from a low socio-economic background, should focus on reducing the home availability of SSB and their intake by parents. Future research should focus on ways of doing so, especially with regard to parents with a lower educational level. By focusing on the association between SES and children's snack consumption, future research should also seek to explain socio-economic inequalities in children's snack consumption.

\section{Acknowledgements}

The present study was financially supported by the Netherlands Organisation for Health Research and Development (ZonMw; project no. 115100004).

The authors' contributions are as follows: W. J. C. v. A., C. T. M. S. and D. v. d. M. were involved in the design of the study; W. J. C. v. A. was responsible for data collection and statistical 
analyses and drafted the manuscript; C. T. M. S., F. J. v. L., G. R. and D. v. d. M. helped with the interpretation of the data and helped draft the article. All authors read and approved the final manuscript.

None of the authors has any conflicts of interest to declare.

\section{References}

1. Kosti RI \& Panagiotakos DB (2006) The epidemic of obesity in children and adolescents in the world. Cent Eur J Public Health 14, 151-159.

2. Wang Y \& Lobstein T (2006) Worldwide trends in childhood overweight and obesity. Int J Pediatr Obes 1, 11-25.

3. Han JC, Lawlor DA \& Kimm SYS (2010) Childhood obesity. Lancet 375, 1737-1748.

4. Owen CG, Whincup PH, Orfei L, et al. (2009) Is body mass index before middle age related to coronary heart disease risk in later life? Evidence from observational studies. Int $J$ Obes (Lond) 33, 866-877.

5. Rennie KL, Johnson L \& Jebb SA (2005) Behavioural determinants of obesity. Best Pract Res Clin Endocrinol Metab 19, 343-358.

6. Wang YC, Bleich SN \& Gortmaker SL (2008) Increasing caloric contribution from sugar-sweetened beverages and $100 \%$ fruit juices among US children and adolescents, 1988-2004. Pediatrics 121, e1604-e1614.

7. Brug J, van Stralen MM, Chinapaw MJM, et al. (2012) Differences in weight status and energy-balance related behaviours according to ethnic background among adolescents in seven countries in Europe: the ENERGY-project. Pediatr Obes 7, 399-411.

8. Van Lippevelde W, te Velde SJ, Verloigne M, et al. (2013) Associations between home- and family-related factors and fruit juice and soft drink intake among 10- to 12-year-old children. The ENERGY project. Appetite 61, 59-65.

9. Piernas C \& Popkin BM (2010) Trends in snacking among U.S. children. Health Aff 29, 398-404.

10. Kelder SH, Perry CL, Klepp KI, et al. (1994) Longitudinal tracking of adolescent smoking, physical activity, and food choice behaviors. Am J Public Health 84, 1121-1126.

11. Craigie AM, Lake AA, Kelly SA, et al. (2011) Tracking of obesity-related behaviours from childhood to adulthood: a systematic review. Maturitas 70, 266-284.

12. Swinburn B, Egger G \& Raza F (1999) Dissecting obesogenic environments: the development and application of a framework for identifying and prioritizing environmental interventions for obesity. Prev Med 29, 563-570.

13. Verloigne M, Van Lippevelde W, Maes L, et al. (2012) Familyand school-based correlates of energy balance-related behaviours in 10-12-year-old children: a systematic review within the ENERGY (EuropeaN Energy balance Research to prevent excessive weight Gain among Youth) project. Public Health Nutr 15, 1380-1395.

14. Lindsay AC, Sussner KM, Kim J, et al. (2006) The role of parents in preventing childhood obesity. Future Child 16, $169-186$.

15. Haerens L, Craeynest M, Deforche B, et al. (2008) The contribution of psychosocial and home environmental factors in explaining eating behaviours in adolescents. Eur J Clin Nutr 62, 51-59.

16. Verloigne M, Van Lippevelde W, Maes L, et al. (2013) Familyand school-based predictors of energy balance-related behaviours in children: a 6-year longitudinal study. Public Health Nutr 16, 202-211.
17. Verzeletti C, Maes L, Santinello M, et al. (2010) Soft drink consumption in adolescence: associations with food-related lifestyles and family rules in Belgium Flanders and the Veneto Region of Italy. Eur J Public Health 20, 312-317.

18. Hendrie G, Sohonpal G, Lange K, et al. (2013) Change in the family food environment is associated with positive dietary change in children. Int J Behav Nutr Phys Act 10, 4.

19. Pearson N, Ball K \& Crawford D (2011) Predictors of changes in adolescents' consumption of fruits, vegetables and energy-dense snacks. Br J Nutr 105, 795-803.

20. Golan M \& Crow S (2004) Parents are key players in the prevention and treatment of weight-related problems. Nutr Rev 62, 39-50.

21. Wouters EJ, Larsen JK, Kremers SP, et al. (2010) Peer influence on snacking behavior in adolescence. Appetite 55, $11-17$.

22. van Ansem WJ, Schrijvers CT \& Rodenburg G, et al. (2014) Child snack consumption: role of parents, peers and child snack purchasing behaviour. Results from the Dutch INPACT study (In the Press).

23. Fletcher A, Bonell C \& Sorhaindo A (2011) You are what your friends eat: systematic review of social network analyses of young people's eating behaviours and bodyweight. $J$ Epidemiol Community Health 65, 548-555.

24. Jensen JD, Bere E, De Bourdeaudhuij I, et al. (2012) Microlevel economic factors and incentives in children's energy balance related behaviours - findings from the ENERGY European cross-section questionnaire survey. Int J Behav Nutr Phys Act 9, 136.

25. NIBUD (National Institute For Family Finance Information) (2012) Pocket Money. http://www.nibud.nl/omgaan-metgeld/kinderen-en-geld/zakgeld.html (accessed August 2013).

26. Roberts BP, Blinkhorn AS \& Duxbury JT (2003) The power of children over adults when obtaining sweet snacks. Int J Peadiatr Dent 13, 76-84.

27. Cutler GJ, Flood A, Hannan P, et al. (2011) Multiple sociodemographic and socioenvironmental characteristics are correlated with major patterns of dietary intake in adolescents. J Am Diet Assoc 111, 230-240.

28. Craig LC, McNeill G, Macdiarmid JI, et al. (2010) Dietary patterns of school-age children in Scotland: association with socio-economic indicators, physical activity and obesity. Br J Nutr 103, 319-334.

29. De Coen V, Vansteelandt S, Maes L, et al. (2012) Parental socioeconomic status and soft drink consumption of the child. The mediating proportion of parenting practices. Appetite 59, 76-80.

30. Vereecken C, Keukelier E \& Maes L (2004) Influence of mother's educational level on food parenting practices and food habits of young children. Appetite 43, 93-103.

31. Danielzik S, Czerwinski-Mast M, Langnäse K, et al. (2004) Parental overweight, socioeconomic status and high birth weight are the major determinants of overweight and obesity in 5-7 y-old children: baseline data of the Kiel Obesity Prevention Study (KOPS). Int J Obes Relat Metab Disord 28, 1494-1502.

32. Winkleby MA, Jatulis DE, Frank E, et al. (1992) Socioeconomic status and health: how education, income, and occupation contribute to risk factors for cardiovascular disease. Am J Public Health 82, 816-820.

33. Bogers RP, Van Assema P, Kester ADM, et al. (2004) Reproducibility, validity, and responsiveness to change of a short questionnaire for measuring fruit and vegetable intake. $\mathrm{Am}$ J Epidemiol 159, 900-909.

34. Haraldsdóttir J, Thórsdóttir I, De Almeida MDV, et al. (2005) Validity and reproducibility of a precoded questionnaire to 
assess fruit and vegetable intake in European 11- to 12-yearold schoolchildren. Ann Nutr Metab 49, 221-227.

35. Van der Horst K, Oenema A, van de Looij-Jansen P, et al. (2008) The ENDORSE study: research into environmental determinants of obesity related behaviors in Rotterdam schoolchildren. BMC Public Health 8, 142.

36. Gattshall ML, Shoup JA, Marshall JA, et al. (2008) Validation of a survey instrument to assess home environments for physical activity and healthy eating in overweight children. Int J Behav Nutr Phys Act 5, 3.

37. Cole TJ, Bellizzi MC, Flegal KM, et al. (2000) Establishing a standard definition for child overweight and obesity worldwide: international survey. BMJ 320, 1240.

38. Baron RM \& Kenny DA (1986) The moderator-mediator variable distinction in social psychological research: conceptual, strategic, and statistical considerations. J Pers Soc Psychol 51, 1173-1182.

39. Chapelot D (2011) The role of snacking in energy balance: a biobehavioral approach. J Nutr 141, 158-162.
40. Hupkens CL, Knibbe RA, Van Otterloo AH, et al. (1998) Class differences in the food rules mothers impose on their children: a cross-national study. Soc Sci Med 7, 1331-1339.

41. Bruening M, Eisenberg M, MacLehose R, et al. (2012) Relationship between adolescents' and their friends' eating behaviors: breakfast, fruit, vegetable, whole-grain, and dairy intake. J Acad Nutr Diet 112, 1608-1613.

42. Fitzgerald A, Heary C, Kelly C, et al. (2013) Self-efficacy for healthy eating and peer support for unhealthy eating are associated with adolescents' food intake patterns. Appetite 63, 48-58.

43. Heim S, Bauer KW, Stang J, et al. (2011) Can a communitybased intervention improve the home food environment? Parental perspectives of the influence of the delicious and nutritious garden. J Nutr Educ Behav 43, 130-134.

44. Baranowski T, Davis M, Resnicow K, et al. (2000) Gimme 5 fruit, juice, and vegetables for fun and health: outcome evaluation. Health Educ Behav 27, 96-111. 